\title{
Activation of Sirtuin 1 Attenuates High Glucose-Induced Neuronal Apoptosis by Deacetylating p53
}

\author{
Xiajie Shi ${ }^{1,2}$, Linhua Pi ${ }^{1}$, Shanlei Zhou ${ }^{1}$, Xin $\mathrm{Li}^{3}$, Fangyuan Min ${ }^{3}$, Shan Wang ${ }^{3}$, \\ Zhenqi $\mathrm{Liu}^{4}$ and Jing $\mathrm{Wu}^{1 *}$
}

${ }^{1}$ Department of Endocrinology, Xiangya Hospital, Central South University, Changsha, China, ${ }^{2}$ Department of Metabolism and Endocrinology, The Second Xiangya Hospital, Central South University, Changsha, China, ${ }^{3}$ Department of Pharmaceutical Engineering, College of Chemistry and Chemical Engineering, Central South University, Changsha, China, ${ }^{4}$ Division of Endocrinology and Metabolism, Department of Medicine, University of Virginia Health System, Charlottesville, VA, United States

\section{OPEN ACCESS}

Edited by:

Åke Sjöholm,

Gävle Hospital, Sweden

Reviewed by:

Dan Lindholm,

University of Helsinki, Finland

Serenella Anzilotti,

IRCCS SDN, Italy

Xiaoqiang Tang,

West China Second

University Hospital of Sichuan

University, China

*Correspondence:

Jing Wu

wujing0731@163.com

Specialty section: This article was submitted to Diabetes,

a section of the journal Frontiers in Endocrinology

Received: 11 February 2018 Accepted: 09 May 2018

Published: 28 May 2018

Citation: Shi X, Pi L, Zhou S, LiX, Min F, Wang S, Liu Z and Wu J (2018) Activation of Sirtuin 1 Attenuates High Glucose-Induced Neuronal Apoptosis by Deacetylating p53.

Front. Endocrinol. 9:274. doi: 10.3389/fendo.2018.00274
Diabetes mellitus (DM) has been proven to be a key risk factor for cognitive impairment. Previous studies have implicated hippocampal neuronal apoptosis in diabetes-related cognitive impairment. However, the underlying mechanism remains unknown. Sirtuin 1 (SIRT1) is a protein deacetylase depended on nicotinamide adenine dinucleotide. Furthermore, it is indispensable in normal learning and memory. Whether SIRT1 is taken part in diabetes-induced neuronal apoptosis and thus involve in the development of diabetic cognitive impairment is still not clear. To address this issue, we examined the possible role of SIRT1 in hippocampal neuronal apoptosis in streptozotocin-induced diabetic mice. Furthermore, the possible mechanism was investigated in high glucoseinduced SH-SY5Y cells. We found that downregulation of the activity and expression of SIRT1 was associated with increased hippocampal neuronal apoptosis in mice. In vitro, cell apoptosis induced by high glucose which was accompanied by a downregulation of SIRT1 and an increased acetylation of p53. On the contrary, activation of SIRT1 using its agonist resveratrol ameliorated cell apoptosis via deacetylating p53. Our data suggest that high concentration of glucose can induce neuronal apoptosis through downregulation of SIRT1 and increased acetylation of p53, which likely contribute to the development of cognitive impairment in diabetes.

Keywords: diabetes, cognitive impairment, sirtuin 1, neuronal apoptosis, p53

\section{INTRODUCTION}

Diabetes has been characterized as a group of metabolic diseases caused by chronic hyperglycemia. Numerous epidemic studies have demonstrated that diabetes increases the risk of the development of cognitive impairment (1-3). With the fast growing number of diabetes and the ever-increasing aging people, diabetic-related diabetic cognitive impairment will challenge public health implication in the future. Therefore, a better insight into the molecular mechanism of the association between diabetes and dementia is of great importance for preventing and slowing the progression of cognitive dysfunction in people with diabetes. Interestingly, several previous studies have indicated that apoptosis in hippocampal neuron promoted the progression of diabetic cognitive dysfunction (4-7). However, the mechanism of neuronal apoptosis in diabetes is still unclear. 
Sirtuin 1 (SIRT1), commonly known as a protein deacetylase depended on nicotinamide adenine dinucleotide $\left(\mathrm{NAD}^{+}\right)$, takes part in cell aging (8), differentiation (9), and apoptosis (10). Due to its deacetylating function, some data have indicated that SIRT1 may reduce cell apoptosis through deacetylating p53 $(11,12)$. p53 responds to various stress signals by modulating the expression of target genes which take part in DNA repair, metabolic pathways, and apoptosis $(13,14)$. Hyperacetylation of p53 has been shown to be positively associated with proapoptotic factors and can be reduced by the deacetylation activity of SIRT1 (15).

Thus, we hypothesized that SIRT1 may get involve in the neuronal apoptosis caused by hyperglycemia in diabetes via p53 signal pathway. To confirm the hypothesis, the expression of SIRT1 in streptozotocin (STZ)-induced diabetic mice and high glucose-treated neuroblastoma cells were measured. Then, we investigated whether activation of SIRT1 had a neuroprotective effect against high glucose-induced neuronal apoptosis via p53 signal pathway. These findings will offer new insights for diabetic cognitive impairment development and progression.

\section{MATERIALS AND METHODS}

\section{Animals and Animal Experiment Procedure}

After 1 week of acclimation, 17 C57BL/6 mice (Department of Laboratory Animals, Central South University) were randomly divided into two groups: the control group $(n=8)$ and the diabetes group $(n=9)$. The mice were raised in animal quarters with comfortable temperature and humidity. All procedures involving animal and their care were conducted in conformity with NIH Guidelines for Care and Use of Laboratory Animals. And the experiment was approved by the institutional animal care committee of Central South University.

After overnight fasting, the mice were modeled diabetes by a single intraperitoneal dose of STZ (Sigma, USA). At the same time, an equivalent volume of vehicle was infused into the control group. 0.1 M sodium citrate buffer ( $\mathrm{pH} 4.4$ ) was used to dissolve STZ. According to the previous study, the dose of $220 \mathrm{mg} / \mathrm{kg}$ was administered (16). To avoid hypoglycemic shock, 5\% glucose was added into the water for $24 \mathrm{~h}$ after STZ injection. Three days after the administration of STZ, the blood from the tail vein was collected to measure the blood glucose for all mice. Mice with non-fasting blood glucose $\geq 16.7 \mathrm{mM}$ in two consecutive tests were considered diabetic.

At the time of sacrifice, mice were anesthetized with pentobarbitol sodium. Then, we exposed the four mice' skulls from each group along the midline and placed the brain on a precooled cutting board for western blotting and SIRT1 activity test, and dissected hippocampus were snapped frozen in liquid nitrogen and preserved at $-70^{\circ} \mathrm{C}$. The remaining brains of mice were perfused with $4 \%$ paraformaldehyde and were then fixed in same solution for hematoxylin-eosin staining and immunohistochemistry staining.

\section{Immunohistochemistry}

Procedures were conducted according to instruction of the Vectastain ABC elite kit (ZSGB-BIO, China). Briefly, paraformaldehyde- fixed tissue sections were deparaffinized and rehydrated. Then, $10 \mathrm{mM}$ sodium citrate ( $\mathrm{pH}$ 6.0) was used to expose the antigen. To inactivate endogenous peroxidase, the slides were incubated with $0.3 \%$ hydrogen peroxide. Primary antibody was incubated overnight at $4^{\circ} \mathrm{C}$ after non-specific binding elimination. Then, the samples were treated with biotinylated secondary antibody for $60 \mathrm{~min}$ at room temperature, with streptavidin-biotin-horseradish peroxidase for another $60 \mathrm{~min}$. 3,3'-Diaminobenzidine was used to visualize. Finally, the sections were counterstained with hematoxylin.

\section{Cell Culture and Differentiation}

SH-SY5Y cells obtained from the State Key Laboratory of Medical Genetics were used in the experiment. SH-SY5Y cells were cultured in DMEM/F12 (Gibco, USA), 10\% fetal bovine serum (FBS; Gibco, USA), and 1\% streptopenicillin (Gibco, USA) at $37^{\circ} \mathrm{C}$ in a humidified cell culture incubator with $5 \%$ carbon dioxide. The human neuroblastoma cells were incubated in the medium containing $1 \%$ FBS for $24 \mathrm{~h}$ and then treated with $10 \mu \mathrm{M}$ all-trans-retinoic acid (RA; Sigma, USA) for 5 days before experiments.

\section{Apoptosis Assay}

According to the result of our previous study, SH-SY5Y cell was cultured in $75 \mathrm{~mm}$ glucose for $96 \mathrm{~h}$ to mimic the high glucose condition in vitro. Cell apoptosis was detected with DAPI nuclear staining. Briefly, after treatment, cells were gently washed with PBS and then stained using DAPI solution (Beyotime, China) for $5 \mathrm{~min}$. The cells were subsequently visualized under a fluorescence microscope (Leica, Germany). To quantify apoptosis, two fields from five wells were blindly analyzed by an observer blinded to the photographers.

\section{SIRT1 Agonist Treatment}

Cells were cultured in $75 \mathrm{mM}$ glucose for $96 \mathrm{~h}$ with or without SIRT1 agonist resveratrol (RV) $(20 \mu \mathrm{M}$; Sigma, USA).

\section{Western Blot}

Proteins were extracted from the whole hippocampus of the mice or SH-SY5Y cells. The protein mass was detected by the bicinchoninic acid protein assay method (Beyotime, China). $50 \mu \mathrm{g}$ of boiled proteins was separated by SDS-PAGE and blotted with anti-caspase-3 (cleaved form; Abacm, USA), anti-Bax antibody (Abcam, USA), anti-Bcl-2 antibody (Abcam, USA), anti-SIRT1 antibody (Abcam, USA), anti-p53 antibody (Abcam, USA), anti-Ace (K382)-p53 (Abcam, USA), and anti- $\beta$ tubulin antibody (Abcam, USA).

\section{SIRT1 Activity}

Sirtuin 1 activity was measured by the SIRT1 colorimetric assay kit (Genmed, China) according to the instruction. Simply, synthesized substrate [Arg-His-Lys-Lys (Ac)] was incubated with hippocampus or SH-SY5Y cells. When SIRT1 is active, the acetylated substrate will be deacetylated, resulting in the change of colorimetric absorbance. The absorbance was detected by a M2 plate reader (Tecan, Austria). 

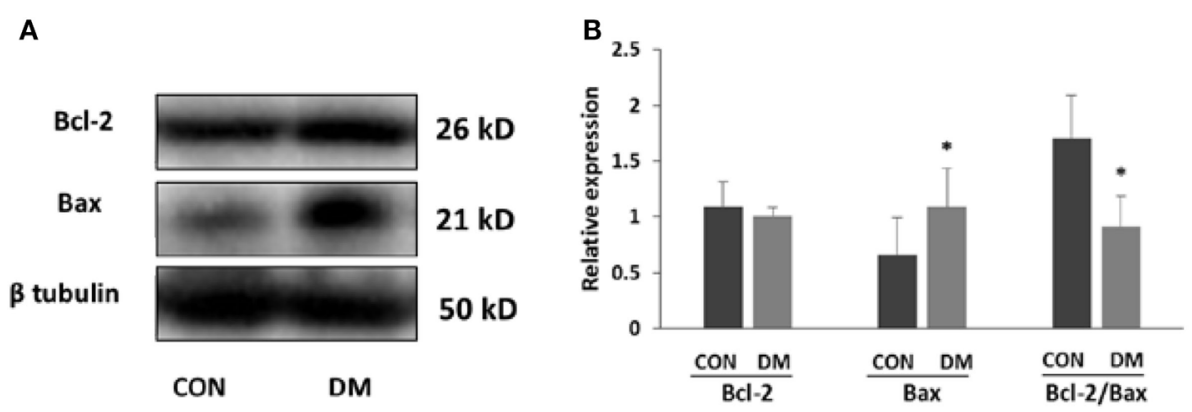

FIGURE 1 | Expression of apoptosis-related proteins in hippocampus of STZ-induced diabetic mice. (A) Representative Western blot gel images of Bcl-2 and Bax. (B) Summarized data of apoptosis-associated protein Bcl-2 and Bax in the hippocampus of STZ-induced diabetic mice and control. All values are expressed as the mean $\pm \mathrm{SD}$. Abbreviations: CON, control; DM, diabetes mellitus. ${ }^{*} P<0.05$ versus control. $N=4$.

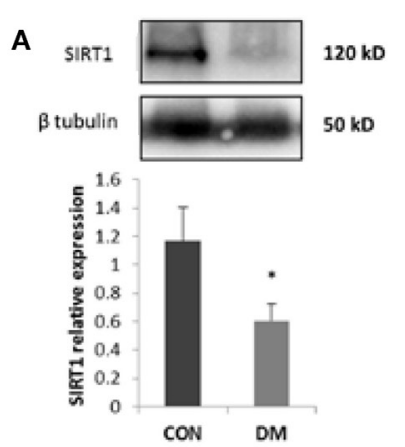

B

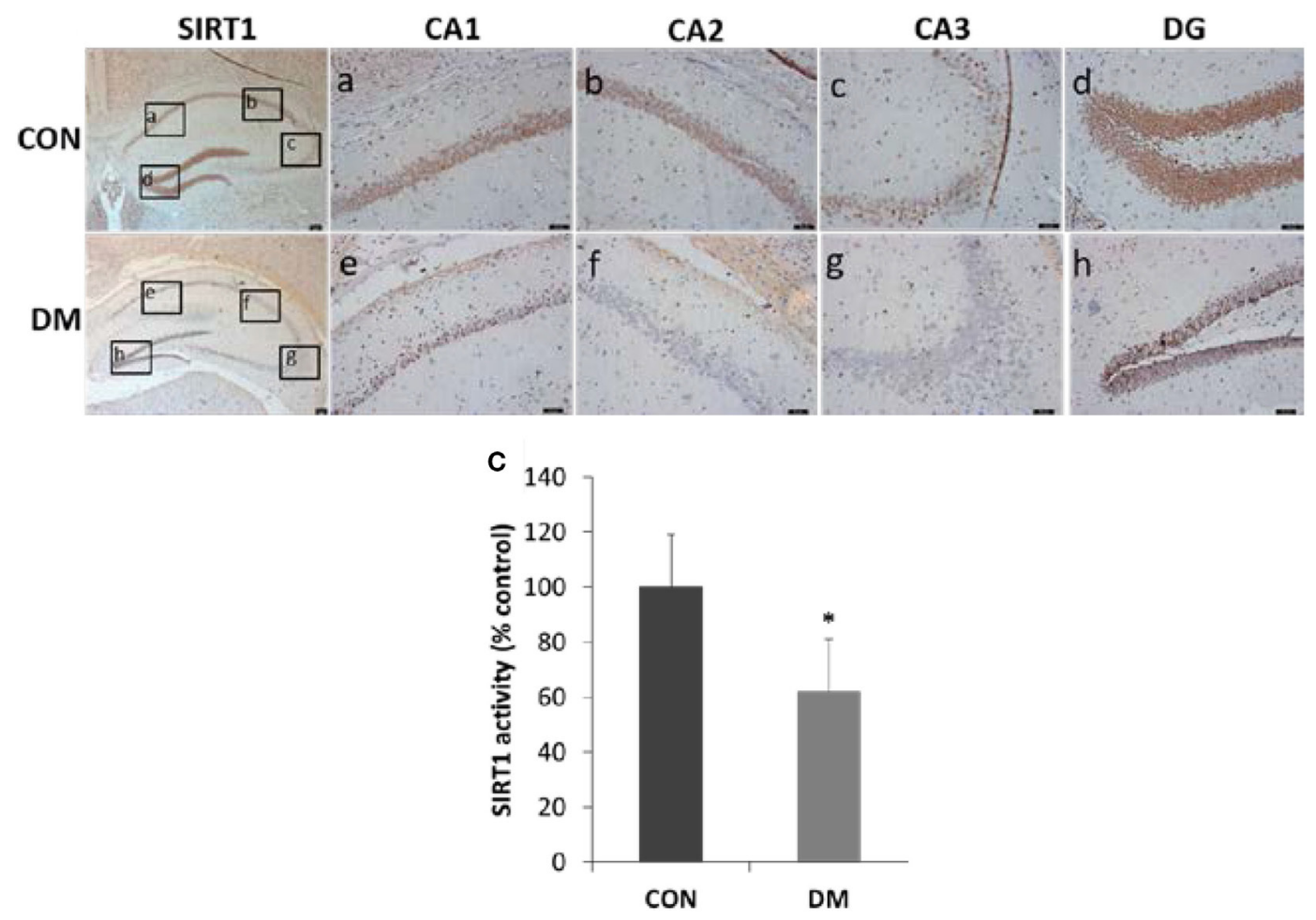

FIGURE 2 | Expression of sirtuin 1 (SIRT1) in hippocampus of STZ-induced diabetic mice. (A) Representative Western blot gel images and quantification data of SIRT1 $(N=4)$. (B) Immunohistochemical stainings of SIRT1. Represent the stainings of CA1, CA2, and CA3 sectors of the hippocampus and dentate gyrus (DG) in control group or diabetes group is shown in panel [(B), a-d or e-h], respectively. Scale bars: $50 \mu \mathrm{m}$. (C) SIRT1 activity $(N=4)$. All values are expressed as the mean \pm SD. Abbreviations: CON, control; DM, diabetes mellitus. ${ }^{*} P<0.05$ versus control. 


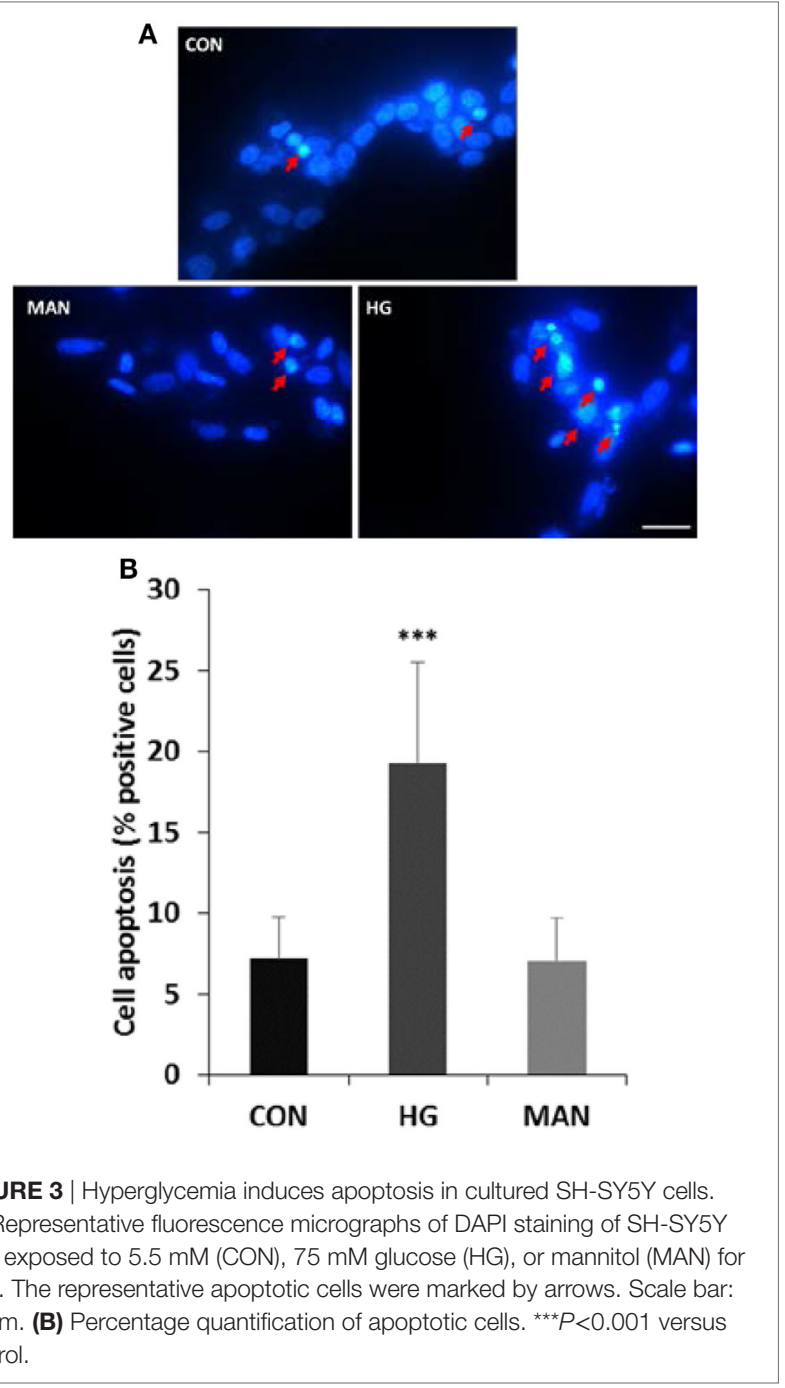

\section{Statistical Analysis}

Independent $t$-test or Cochran and Cox $t$-test for continuous data was performed for comparison of two groups. Statistical analyses were performed with SPSS for windows (version 17.0). The significance level $\alpha$ is 0.05 .

\section{RESULTS}

\section{Hippocampus Neuronal Apoptosis in STZ-Induced Diabetic Mice}

At the fourth week after STZ administration, changes in apoptosis-related proteins in hippocampus were examined. The protein levels of Bax (a protein facilitating apoptotic cell death) and Bcl-2 (a protein that is protective of apoptotic cell death) were measured by western blotting. In 4-week diabetic mice, the Bax expression was significantly increased. However, the level of Bcl-2 was not changed in diabetic mice. Nevertheless, our results showed that the ratio of $\mathrm{Bcl}-2$ to Bax was significantly decreased (Figure 1, $P<0.05$ ), indicating the enhanced neuronal apoptosis in hyperglycemia mice.

\section{SIRT1 Is Decreased in Hippocampus Neuron of STZ-Induced Diabetic Mice}

Sirtuin 1 expression and activity in hippocampus was detected after STZ administration of male C57BL/6J mice. Four weeks after STZ treatment, both SIRT1 levels and activities were decreased in hippocampus. To locate the alteration of SIRT1 in hippocampus, immunostaining was used. We found SIRT1 mainly decreased in cognition-associated areas such as CA1, CA3, and dentate gyrus (DG) (Figure 2).

\section{Effect of High Glucose on SH-SY5Y Cells Apoptosis}

Differentiated SH-SY5Y cells were cultured in $75 \mathrm{mM}$ glucose or $69.5 \mathrm{mM}$ mannitol (MAN) (plus $5.5 \mathrm{mM}$ glucose in DMEM/ F12 medium) for $96 \mathrm{~h}$, and the cell apoptosis was measured with DAPI staining. A small number of apoptotic cells (7.2\%) were measured in the control group. However, 19.3\% apoptotic cells were detected by DAPI staining after high glucose treatment. Similar with the control group, the apoptotic rate in cells treated with MAN was $7.1 \%$ (Figure 3).

\section{Alteration of SIRT1 and p53 in SH-SY5Y Cells Under High Glucose Condition}

Differentiated neuroblastoma cells were cultured with $75 \mathrm{mM}$ glucose for $96 \mathrm{~h}$ to explore whether high glucose could induce downregulation of SIRT1. Similar with the results in diabetic mice, both activity and expression of SIRT1 decreased significantly in high glucose-incubated SH-SY5Y cells. To investigate the possible mechanism between the downregulation of SIRT1 and cell apoptosis, we examined $\mathrm{p} 53$ protein by the Western blotting. The results showed an increase in acetylated p53 protein in cells treated with high glucose (Figure 4). To further characterize the trait of apoptotic mechanism, the status of Bax, Bcl-2, and caspase-3 was tested. SH-SY5Y cells showed a dramatic decrease in the ratio of $\mathrm{Bcl}-2$ to $\mathrm{Bax}$ and an increase in the expression of caspase- 3 under high glucose condition (Figure 4), suggesting that high glucose-induced apoptosis possibly be mediated by the mitochondrial pathway. Based on the above results, we guessed that SIRT1 may induce neuronal apoptosis through p53/Bax pathway.

\section{Activation of SIRT1 Alleviated Cell Apoptosis via Decreasing p53 Acetylation}

To explore the effects of SIRT1 activation on the differentiated SH-SY5Y cells, SIRT1 agonist RV was applied. Activation of SIRT1 significantly reduced the amount of apoptotic or necrotic cells induced by high glucose. As shown in Figure 5, the number of cells with positive DAPI staining was $12.3 \%$ in the presence of RV. However, without activator, the number reached up to $23.4 \%$.

Then, we examined whether activation of SIRT1 could decrease the acetylated p53 level. Just as results shown in Figure 5, treatment with RV raised the SIRT1 expression and reduced the acetylated p53 level compared with cells incubated with high concentration of glucose. 

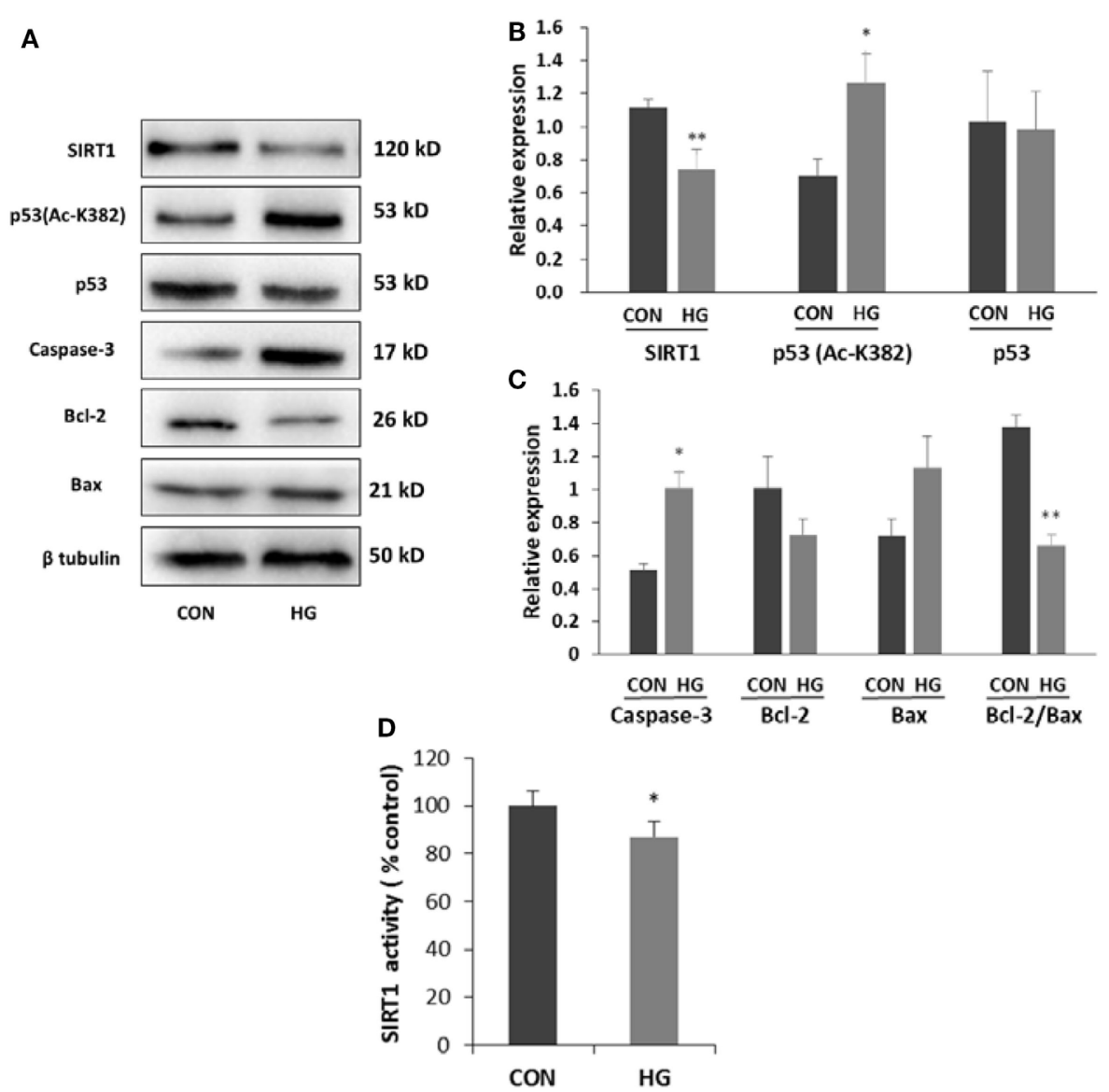

FIGURE 4 | Effects of high glucose on the expressions of sirtuin 1 (SIRT1), p53, Ac-p53, and apoptosis-associated proteins. SH-SY5Y cells were cultured in either $5.5 \mathrm{mM}(\mathrm{CON})$ or $75 \mathrm{mM}(\mathrm{HG})$ glucose-containing media for $96 \mathrm{~h}$. (A) Representative Western blot images. (B) Quantifications of SIRT1, p53 (Ac-K382), and p53 expression. (C) Quantifications of caspase-3, Bcl-2, Bax, and Bcl-2/Bax expression. (D) SIRT1 activity. ${ }^{*} P<0.05 ;{ }^{* *} P<0.01$ versus control. $N=3$.

To further support these findings, several proteins associated with apoptotic cascade were assayed. The high glucose-induced increase of caspase- 3 and the decline of the $\mathrm{Bcl}-2 / \mathrm{Bax}$ ratio were both partially reversed in the cells in the presence of SIRT1 activator.

\section{DISCUSSION}

The major aim of our work was to explore whether SIRT1 is involved in neuronal apoptosis induced by diabetes. Using STZ-induced diabetic mice and in vitro cultured differentiated SH-SY5Y cells, we found SIRT1 was obviously decreased. Activation of SIRT1 could alleviate high glucose-induced cell apoptosis by deacetylate p53. These findings revealed a novel molecular mechanism involving neuronal apoptosis in diabetes mellitus.

There has been a wide recognition that type $1 \mathrm{DM}$ (T1DM) can cause cognitive impairment $(17,18)$. STZ is a commonly used reagent to model T1DM due to its preferentially toxic to beta cells in pancreas. Substantial evidence and our previous studies have demonstrated that single high dose of STZ can induced diabetic cognitive dysfunction at early stages of DM $(19,20)$. Hippocampus, an internal structure of the brain, plays a very important role in several key fields of cognitive function, such as spatial navigation, memory, and learning $(21,22)$. And previous studies have indicated that hippocampal neuronal apoptosis has close connection with diabetic cognitive impairment (23-26). Therefore, clarify of the mechanism in hippocampal neuronal apoptosis in diabetes will contribute a lot to the prevention and treatment for the diabetic cognitive impairment.

Sirtuin 1 is widely expressed and has been shown to be highly expressed in the developing mouse central nervous system (27), adult mouse and human brain (28). In the adult brain, SIRT1 is expressed in the most brain areas and is prominent in the hippocampal neuron (29), which is replicated in our results. Furthermore, SIRT1 was found highly decreased in the hippocampus with neuronal apoptosis, especially in the CA1, CA3, and DG subregions, which is closely related with memory and learning (30). And the activity of SIRT1 was also decreased. Bcl-2 family consists of a group of cytoplasmic proteins and is notable for its regulation of cell apoptosis. There 

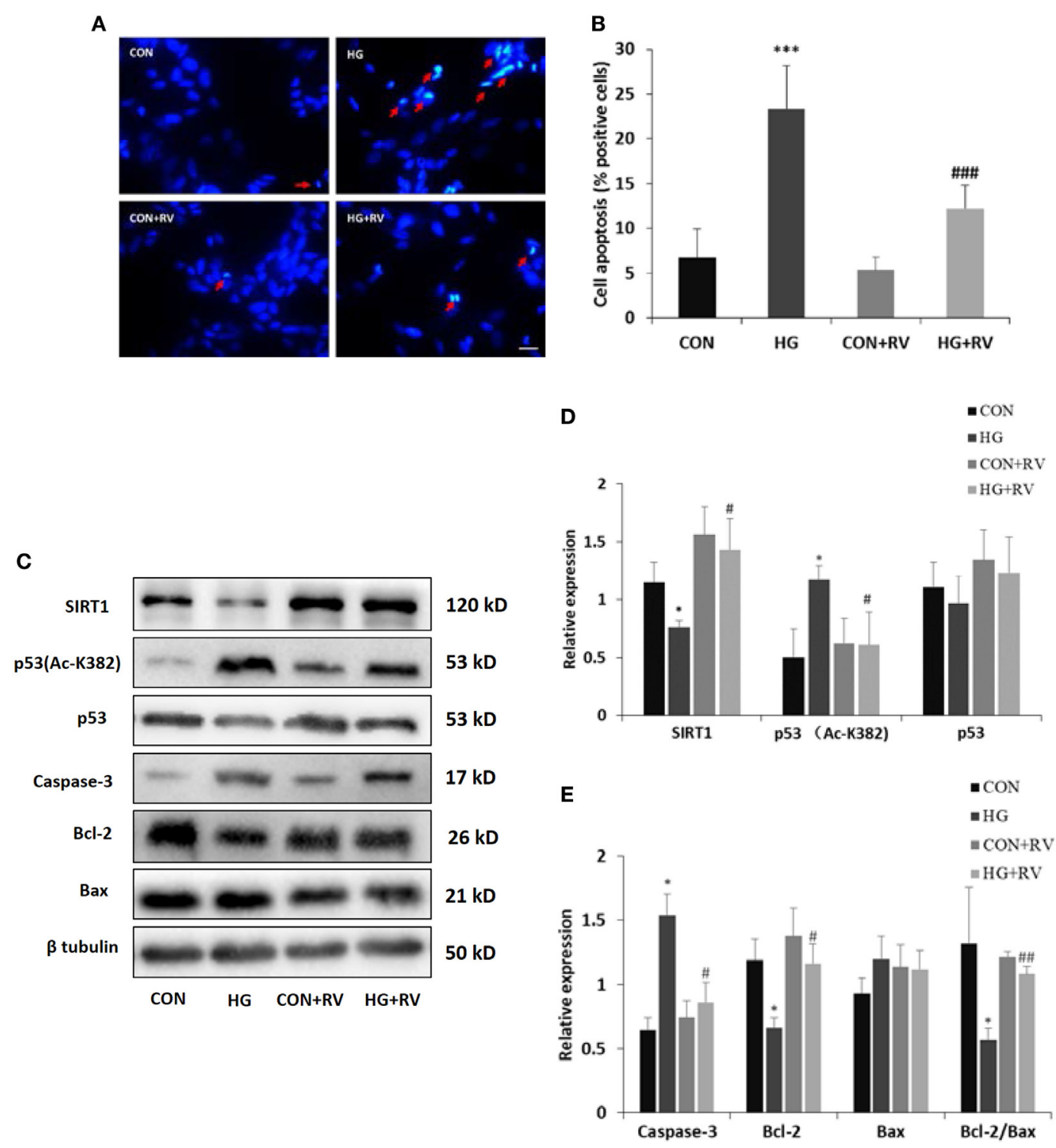

FIGURE 5 | Activation of sirtuin 1 (SIRT1) attenuates high glucose-induced cell apoptosis via deacetylating p53. SH-SY5Y cells were cultured in HG media for $96 \mathrm{~h}$ in the presence of $10 \mu \mathrm{M}$ resveratrol (RV). (A) Representative fluorescence micrographs of DAPI staining of SH-SY5Y cells treated with or without RV. Arrow denotes cell apoptosis. (B) Quantification of cell apoptosis. (C) Representative Western blot images of protein expression. (D) Quantifications of SIRT1, p53 (Ac-K382), and p53 expression. (E) Quantifications of Caspase-3, Bcl-2, Bax, and Bcl-2/Bax expression. ${ }^{\star} P<0.05$; ${ }^{\star \star} P<0.01$; and ${ }^{\star \star \star} P<0.001$ versus control. ${ }^{\sharp} P<0.05$; $\# P<0.01$; and ${ }^{\# \# P}<0.01$ versus HG. Scale bar: $20 \mu \mathrm{m} . N=3$.

are two main proteins in this family, Bcl-2 and Bax. However, they are functionally opposite: Bax promotes apoptosis, whereas $\mathrm{Bcl}-2$ counteracts this effect (31). And the ratio of Bcl-2 to Bax controls the cell life after an apoptotic stimulus. We found in this study, the ratio of $\mathrm{Bcl}-2$ to Bax decreased in hippocampus of diabetic mice than that of the controls. These results indicated that hippocampal neuronal apoptosis in STZ-induced diabetic mice appeared to correlate with SIRT1. Thus, further study was conducted in vitro.

SH-SY5Y cell line, derived from SK-N-SH, is a widely used model for studying the neuronal mechanism. SH-SY5Y cells are able to differentiate into neuronal lineage by all-trans-RA treatment (32). Our previous study have proved that culturing differentiated SH-SY5Y cell in $75 \mathrm{mM}$ glucose for $96 \mathrm{~h}$ is an appropriate choice to mimic high glucose condition in vitro. Another study also proved that SH-SY5Y cell cultured in high glucose (above $50 \mathrm{mM}$ ) occured hyperglycemic stress and cell injury (33). Our results indicated that the apoptotic cells were increased in the high glucose-cultured group. Besides, the ratio of Bcl-2 to Bax and the expression of caspase- 3 were both changed in high glucose-cultured neuroblastoma cells. Similar with the findings in vivo, these results further indicated that glucose at high concentration could induce cell apoptosis through the mitochondria pathway. 
Previous studies have proved that p53 can be deacetylated by SIRT1 by overexpression and dominant-negative strategies both in vitro and in vivo $(11,15)$. Multiple lysine residues of p53 can be acetylated in human, including K320, K373, and K382 (11). Acetylation at different residues induces diverse aspects of p53-mediated stress response. Acetylation of p53 on K382 residue facilitates $\mathrm{p} 53$ activation, which triggers the transcription of target genes associated with apoptosis (34). Our results showed that the increasing of acetylation of p53 K382 accompanied by decreasing of SIRT1. These findings strongly suggested that the decline of SIRT1 induced by high glucose resulted in acetylation of p53 at K382 lysine residues, which could mediate neuronal apoptosis.

Resveratrol is a well-known agonist of SIRT1 (35). So, we used $\mathrm{RV}$ in SH-SY5Y cells with neuron-like phenotypes to further prove the above view. This work indicated that the high glucoseinduced decreasing of SIRT1 was reversed with RV. Then, we detected the effect of activation of SIRT1 on cell apoptosis and apoptosis-related protein. The most important finding of this work is that activation of SIRT1 can partially reverse the SH-SY5Y cell apoptosis mediated by high concentration of glucose. The reverse of the apoptosis-related protein, caspase- 3 and the ratio of Bcl-2 to Bax, further confirmed it. Some previous studies also reported that RV had protective effect in the neuronal survival $(36,37)$. Although previous studies indicate that the activation of SIRT1 is a key aspect of RV action, the interaction between RV and other factors cannot be rule out.

Taken together, we demonstrate that decreasing of SIRT1 and neuronal apoptosis occures in the STZ-induced diabetic mice.

\section{REFERENCES}

1. Roberts RO, Knopman DS, Geda YE, Cha RH, Pankratz VS, Baertlein L, et al. Association of diabetes with amnestic and nonamnestic mild cognitive impairment. Alzheimers Dement (2014) 10(1):18-26. doi:10.1016/j.jalz. 2013.01.001

2. Hilal S, Ikram MK, Saini M, Tan CS, Catindig JA, Dong YH, et al. Prevalence of cognitive impairment in Chinese: epidemiology of dementia in Singapore study. J Neurol Neurosurg Psychiatry (2013) 84(6):686-92. doi:10.1136/jnnp2012-304080

3. Fu Z, Wu J, Nesil T, Li MD, Aylor KW, Liu Z. Long-term high-fat diet induces hippocampal microvascular insulin resistance and cognitive dysfunction. Am J Physiol Endocrinol Metab (2017) 312(2):E89-97. doi:10.1152/ ajpendo.00297.2016

4. Liu J, Feng L, Ma D, Zhang M, Gu J, Wang S, et al. Neuroprotective effect of paeonol on cognition deficits of diabetic encephalopathy in streptozotocin-induced diabetic rat. Neurosci Lett (2013) 549:63-8. doi:10.1016/j. neulet.2013.06.002

5. Ye L, Wang F, Yang RH. Diabetes impairs learning performance and affects the mitochondrial function of hippocampal pyramidal neurons. Brain Res (2011) 1411:57-64. doi:10.1016/j.brainres.2011.07.011

6. Guo YJ, Wang SH, Yuan Y, Li FF, Ye KP, Huang Y, et al. Vulnerability for apoptosis in the hippocampal dentate gyrus of STZ-induced diabetic rats with cognitive impairment. J Endocrinol Invest (2014) 37(1):87-96. doi:10.1007/ s40618-013-0030-0

7. Wang S, Zhou SL, Min FY, Ma JJ, Shi XJ, Bereczki E, et al. mTOR-mediated hyperphosphorylation of tau in the hippocampus is involved in cognitive deficits in streptozotocin-induced diabetic mice. Metab Brain Dis (2014) 29(3):729-36. doi:10.1007/s11011-014-9528-1

8. Satoh A, Brace CS, Rensing N, Cliften P, Wozniak DF, Herzog ED, et al. Sirtl extends life span and delays aging in mice through the regulation of
In high glucose-incubated SH-SY5Y cells, decreasing of SIRT1, p53 acetylation, and cell apoptosis are confirmed, and activation of SIRT1 by RV attenuate the cell apoptosis via deacetylation of p53. It is therefore suggested that SIRT1 may be a therapeutic target for the treatment of diabetic cognitive impairment.

\section{ETHICS STATEMENT}

All procedures involving animal and their care were conducted in conformity with NIH Guidelines for Care and Use of Laboratory Animals, and the experiment was approved by the institutional animal care committee of Central South University.

\section{AUTHOR CONTRIBUTIONS}

JW and SW designed the experiments. The experimental procedures were performed by XS, LP, SZ, XL, and FM. XS and JW prepared the manuscript. ZL revised the manuscript.

\section{ACKNOWLEDGMENTS}

This study was mainly completed in the Institute of Medical Sciences, Xiangya Hospital of Central South University.

\section{FUNDING}

This study was supported by the National Natural Science Foundation of China $(81170754,81373394)$.
Nk2 homeobox 1 in the DMH and LH. Cell Metab (2013) 18(3):416-30. doi:10.1016/j.cmet.2013.07.013

9. Liu DJ, Hammer D, Komlos D, Chen KY, Firestein BL, Liu AY. SIRT1 knockdown promotes neural differentiation and attenuates the heat shock response. J Cell Physiol (2014) 229(9):1224-35. doi:10.1002/jcp.24556

10. Xiong H, Pang J, Yang H, Dai M, Liu Y, Ou Y, et al. Activation of miR-34a/ SIRT1/p53 signaling contributes to cochlear hair cell apoptosis: implications for age-related hearing loss. Neurobiol Aging (2015) 36(4):1692-701. doi:10.1016/j.neurobiolaging.2014.12.034

11. Cheng HL, Mostoslavsky R, Saito S, Manis JP, Gu Y, Patel P, et al. Developmental defects and p53 hyperacetylation in Sir2 homolog (SIRT1)-deficient mice. Proc Natl Acad Sci U S A (2003) 100(19):10794-9. doi:10.1073/pnas. 1934713100

12. Wang N, Zhang F, Yang L, Zou J, Wang H, Liu K, et al. Resveratrol protects against L-arginine-induced acute necrotizing pancreatitis in mice by enhancing SIRT1-mediated deacetylation of $\mathrm{p} 53$ and heat shock factor 1. Int J Mol Med (2017) 40(2):427-37. doi:10.3892/ijmm.2017.3012

13. Sen N, Kumari R, Singh MI, Das S. HDAC5, a key component in temporal regulation of p53-mediated transactivation in response to genotoxic stress. Mol Cell (2013) 52(3):406-20. doi:10.1016/j.molcel.2013.09.003

14. Yang W, Lu J, Weng J, Jia W, Ji L, Xiao J, et al. Prevalence of diabetes among men and women in China. N Engl J Med (2010) 362(12):1090-101. doi:10.1056/ NEJMoa0908292

15. Li M, Lu Y, Hu Y, Zhai X, Xu W, Jing H, et al. Salvianolic acid B protects against acute ethanol-induced liver injury through SIRT1-mediated deacetylation of p53 in rats. Toxicol Lett (2014) 228(2):67-74. doi:10.1016/j.toxlet. 2014.04.011

16. Ferber S, Halkin A, Cohen H, Ber I, Einav Y, Goldberg I, et al. Pancreatic and duodenal homeobox gene 1 induces expression of insulin genes in liver and ameliorates streptozotocin-induced hyperglycemia. Nat Med (2000) 6(5):568-72. doi:10.1038/75050 
17. Nunley KA, Rosano C, Ryan CM, Jennings JR, Aizenstein HJ, Zgibor JC, et al. Clinically relevant cognitive impairment in middle-aged adults with childhood-onset type 1 diabetes. Diabetes Care (2015) 38(9):1768-76. doi:10.2337/ dc15-0041

18. Kirchhoff BA, Jundt DK, Doty T, Hershey T. A longitudinal investigation of cognitive function in children and adolescents with type 1 diabetes mellitus. Pediatr Diabetes (2016). doi:10.1111/pedi.12414

19. Beauquis J, Roig P, De Nicola AF, Saravia F. Short-term environmental enrichment enhances adult neurogenesis, vascular network and dendritic complexity in the hippocampus of type 1 diabetic mice. PLoS One (2010) 5(11): e13993. doi:10.1371/journal.pone.0013993

20. Huang HJ, Chen YH, Liang KC, Jheng YS, Jhao JJ, Su MT, et al. Exendin-4 protected against cognitive dysfunction in hyperglycemic mice receiving an intrahippocampal lipopolysaccharide injection. PLoS One (2012) 7(7):e39656. doi:10.1371/journal.pone.0039656

21. Buzsaki G, Moser EI. Memory, navigation and theta rhythm in the hippocampal-entorhinal system. Nat Neurosci (2013) 16(2):130-8. doi:10.1038/ nn.3304

22. Gruart A, Leal-Campanario R, Lopez-Ramos JC, Delgado-Garcia JM. Functional basis of associative learning and their relationships with long-term potentiation evoked in the involved neural circuits: lessons from studies in behaving mammals. Neurobiol Learn Mem (2015) 124:3-18. doi:10.1016/j. nlm.2015.04.006

23. Sun LJ, Hou XH, Xue SH, Yan F, Dai YJ, Zhao CH, et al. Fish oil modulates glycogen synthase kinase-3 signaling pathway in diabetes-induced hippocampal neurons apoptosis. Brain Res (2014) 1574:37-49. doi:10.1016/j.brainres. 2014.05.050

24. Li ZG, Zhang W, Grunberger G, Sima AA. Hippocampal neuronal apoptosis in type 1 diabetes. Brain Res (2002) 946(2):221-31. doi:10.1016/S0006-8993 (02)02887-1

25. Sima AA, Li ZG. The effect of C-peptide on cognitive dysfunction and hippocampal apoptosis in type 1 diabetic rats. Diabetes (2005) 54(5):1497-505. doi:10.2337/diabetes.54.5.1497

26. Wu J, Nie SD, Wang S. Tau pathology in diabetes mellitus. Pharmazie (2013) 68(8):649-52. doi:10.1691/ph.2013.2901

27. Ogawa T, Wakai C, Saito T, Murayama A, Mimura Y, Youfu S, et al. Distribution of the longevity gene product, SIRT1, in developing mouse organs. Congenit Anom (Kyoto) (2011) 51(2):70-9. doi:10.1111/j.1741-4520.2010.00304.x

28. Zakhary SM, Ayubcha D, Dileo JN, Jose R, Leheste JR, Horowitz JM, et al. Distribution analysis of deacetylase SIRT1 in rodent and human nervous systems. Anat Rec (Hoboken) (2010) 293(6):1024-32. doi:10.1002/ar.21116
29. Michan S, Li Y, Chou MM, Parrella E, Ge H, Long JM, et al. SIRT1 is essential for normal cognitive function and synaptic plasticity. JNeurosci (2010) 30(29):9695-707. doi:10.1523/JNEUROSCI.0027-10.2010

30. Kesner RP. Behavioral functions of the CA3 subregion of the hippocampus. Learn Mem (2007) 14(11):771-81. doi:10.1101/lm.688207

31. Siddiqui WA, Ahad A, Ahsan H. The mystery of BCL2 family: Bcl-2 proteins and apoptosis: an update. Arch Toxicol (2015) 89(3):289-317. doi:10.1007/ s00204-014-1448-7

32. Lopes FM, Schroder R, Da FMJ, Zanotto-Filho A, Muller CB, Pires AS, et al. Comparison between proliferative and neuron-like SH-SY5Y cells as an in vitro model for Parkinson disease studies. Brain Res (2010) 1337:85-94. doi:10.1016/j.brainres.2010.03.102

33. Hsu YY, Tseng YT, Lo YC. Berberine, a natural antidiabetes drug, attenuates glucose neurotoxicity and promotes Nrf2-related neurite outgrowth. Toxicol Appl Pharmacol (2013) 272(3):787-96. doi:10.1016/j.taap.2013.08.008

34. Wang J, Qian J, Hu Y, Kong X, Chen H. ArhGAP30 promotes p53 acetylation and function in colorectal cancer. Nat Commun (2014) 5:4735. doi:10.1038/ ncomms5735

35. Zhang W, Luo J, Yang F, Wang Y, Yin Y, Strom A, et al. BRCA1 inhibits AR-mediated proliferation of breast cancer cells through the activation of SIRT1. Sci Rep (2016) 6:22034. doi:10.1038/srep22034

36. Kim D, Nguyen MD, Dobbin MM, Fischer A, Sananbenesi F, Rodgers JT, et al. SIRT1 deacetylase protects against neurodegeneration in models for Alzheimer's disease and amyotrophic lateral sclerosis. EMBO J (2007) 26(13):3169-79. doi:10.1038/sj.emboj.7601758

37. Kairisalo M, Bonomo A, Hyrskyluoto A, Mudo G, Belluardo N, Korhonen L, et al. Resveratrol reduces oxidative stress and cell death and increases mitochondrial antioxidants and XIAP in PC6.3-cells. Neurosci Lett (2011) 488(3): 263-6. doi:10.1016/j.neulet.2010.11.042

Conflict of Interest Statement: The authors declare that the research was conducted in the absence of any commercial or financial relationships that could be construed as a potential conflict of interest.

Copyright $\odot 2018$ Shi, Pi, Zhou, Li, Min, Wang, Liu and Wu. This is an open-access article distributed under the terms of the Creative Commons Attribution License (CC $B Y)$. The use, distribution or reproduction in other forums is permitted, provided the original author(s) and the copyright owner are credited and that the original publication in this journal is cited, in accordance with accepted academic practice. No use, distribution or reproduction is permitted which does not comply with these terms. 